\title{
PELATIHAN PEMBUATAN BEDCOVER KACA (KAIN PERCA) UNTUK BEKAL WIRAUSAHA DI PANTI ASUHAN BINA INSANI NGAWI
}

\author{
Ratih Kusuma Dewi ${ }^{1 a}$, Afi'ah Citra Nur Mualifah¹, Alfian Viki Praditya ${ }^{1}$
}

Abstract: The aim of Bedcover Training is to train skill and capability in enterpreunership of orphanage students as skill capital to create business chance and independent business field. The training was held in Bina Insani Orphanage in Ngawi on May $25^{\text {th }}-26^{\text {th }}, 2017$. The members are 40 students and divided into 8 small groups. The training produces 5 sheets of bedcover. The training of making bedcover is intended for arousing innovative thinking of Ngawi Bina Insani Orphanage students. The making bedcover is aimed to economize raw material by utilizing some wasted materials.

Keywords: Bina Insani Orphanage, Patchwork Bedcover, Training.

\section{JURNAL PENGABDIAN PADA MASYARAKAT}

Website: http://ojs.ejournal.id/index.php/ppm

Permalink: http://ojs.ejournal.id/index.php/ppm/article/view/110

How to cite (APA): Dewi, R. K., Mualifah, A. C. N., \& Praditya, A. V. (2017). Pelatihan pembuatan bedcover kaca (kain perca) untuk bekal wirausaha di panti asuhan bina insani Ngawi. Jurnal Pengabdian Pada Masyarakat, 2(1), 57-61.

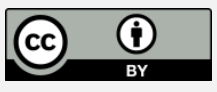

This is an open access article distributed under the terms of the Creative Commons Attribution 4.0 International License, which permits unrestricted use, distribution, and reproduction in any medium, provided the original work is properly cited.

\section{PENDAHULUAN}

Saat ini pekerjaan sebagai pengusaha atau wirausahawan mulai dilirik banyak orang. Wirausaha mengajarkan aspek penting kreativitas dan keberanian dengan adanya hal tersebut, kami mengadakan pelatihan bagi santri Panti Asuhan Bina Insani yang kurang mampu sebagai bentuk kotribusi nyata dalam usaha memandirikan dan memberdayakan mereka. Panti Asuhan di Ngawi cukup banyak. Salah satu panti asuhan yang ada di Ngawi adalah Panti Asuhan Bina Insani yang terletak di Kabupaten Ngawi. Panti Asuhan Bina Insani merupakan salah satu Panti asuhan yang memiliki santri cukup banyak, tetapi belum memiliki sumber dana Panti asuhan secara mandiri.

Panti Asuhan adalah sebuah lembaga pengganti fungsi orang tua bagi anak-anak terlantar dan memiliki tanggung jawab dalam memberikan

${ }^{1}$ Pendidikan Guru Sekolah Dasar, Universitas PGRI Madiun.

a email: ratihkusuma147@gmail.com. 
pelayanan kesejahteraan sosial bagi anak-anak terlantar terutama kebutuhan fisik, mental, dan sosial pada anak asuh supaya mereka memiliki kesempatan untuk mengembangkan dirinya dan menjadi generasi penerus cita-cita bangsa dan sebagai insan yang akan turut serta dalam bidang pembangunan sosial. Melihat fenomena itu, kami dapat melihat sebuah peluang usaha yang sangat besar melalui pemanfaatan limbah kain perca batik sebagai bahan alternatif kerajinan bedcover. Kain perca merupakan bahan limbah yang dapat di daur ulang. Salah satunya menjadi bedcover Dengan inovasi baru yaitu pembuatan Bedcover Kain Perca Batik yang sangat mudah dibuat dan untuk santri panti asuhan dapat memaksimalkan bakat dan potensinya bahkan setelah pelatihan ini kami harapkan dapat menjadi lahan bisnis bagi santi Panti Asuhan Bina Insani Ngawi.

Dengan penanganan yang tepat dan inovatif, perca batik dapat menjadi aset yang berharga dan bernilai ekonomis tinggi. Pengelolaan perca batik sebenarnya telah mendapat perhatian dari berbagai pihak. Beberapa produk yang telah memanfaatkan perca batik yaitu berbagai macam model tas, dompet, sandal, seprai, bedcover dan gantungan kunci. Ini menunjukkan bahwa produk berbahan dasar perca batik telah dikenal oleh masyarakat Indonesia.

\section{METODE PELAKSANAAN}

Mitra dari Pelatihan pengabdian masyarakat ini adalah panti asuhan anak anak yatim piatu di panti asuhan Bina Insani Kota Ngawi, peserta pelatihan adalah anak anak di panti, pelatihan ini kita tujukan pada anak santri putri. Dengan pemateri terdiri dari 3 orang.

Pelatihan ini ditujukan untuk Panti Asuhan Anak Yatim Piatu, yang dilaksanakan di Panti Asuhan Bina Insani. Panti beralamat di Jl. Jekitut No 11 Beran, Ngawi. Peserta pelatihan pembuatan bedcover yaitu santri putri panti asuhan bina insani.

Kegiatan ini Waktu yang diperlukan untuk melaksanakan PPM dari awal penyusunan proposal sampai dengan laporan kegiatan membutuhkan waktu selama kurang lebih 5 bulan, dengan total pertemuan sebanyak 2 kali pertemuan untuk pelaksanaan pelatihan. 


\section{HASIL DAN PEMBAHASAN}

\section{Tahapan Awal (Persiapan)}

Metode yang digunakan dalam kegiatan ini yaitu dilakukan analisis situasi dengan observasi awal dan wawancara kepada pihak terkait dengan tema pengabdian, untuk mengetahui permasalahan yang timbul pada pada mitra. Proses ini dilakukan sebelum penyusunan proposal pengabdian ini. Hasil yang diperoleh didapat dan disajikan pada awal bab proposal pengabdian pada masyarakat ini adalah kendala pada peningkatan skill dan kemampuan peserta panti dalam menjahit dengan mesin jahit, hanya beberapa anak saja yang mampu mengoperasikan mesin jahit.

\section{Tahapan Inti Kegiatan}

Pelatihan pembuatan bedcover kaca (Kain Perca) sesuai urutan seperti pada Gambar 1.

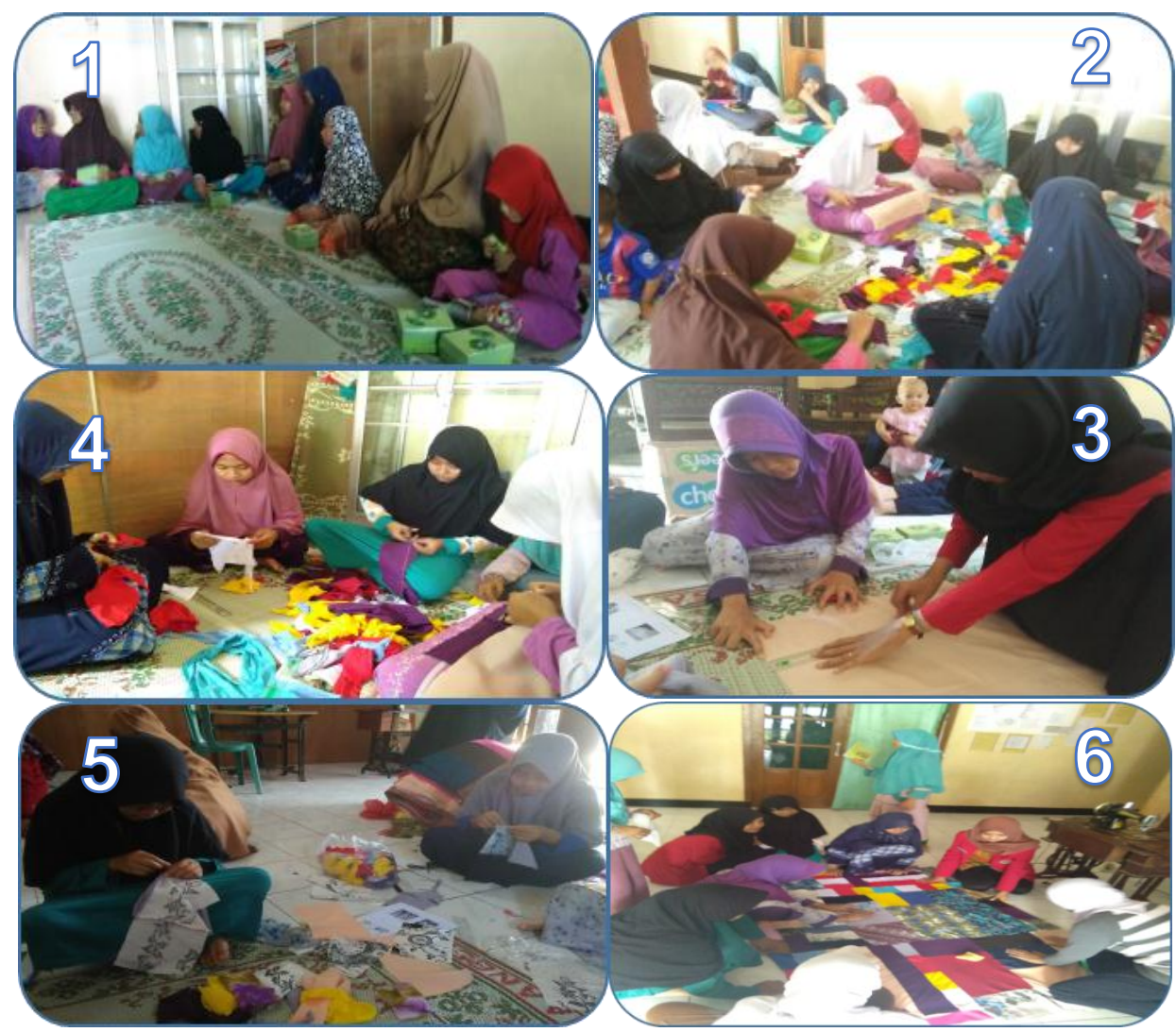

Gambar 1. Urutan Pelaksanaan Pelatihan Pembuatan Bedcover Kaca (Kain Perca) 
Urutan pelaksanaan pelatihan pembuatan bedcover kaca (kain perca) meliputi: 1) Pemilihan kain; 2) mempola kain perca; 3) menggunting kain; 4) menjahit kain perca; 5) menyatukan kain perca dengan busa; dan 6) finishing, sehingga bedcover siap dipakai.

\section{Tahapan Akhir}

Tahapan terakhir dari kegiatan pelatihan ini yaitu membuat laporan akhir yang berisikan laporan pertanggungjawaban pengabdian, sehingga hasil pengabdian ini dapat bermanfaat bagi mitra.

Berdasarkan hasil pembahasan hasil analisis dari pelatihan pembuatan bedcover kaca (Kain Perca) di Panti Asuhan Bina Insani Ngawi yang dilaksanakan selama lima bulan mendapat respon yang positif dari santri panti asuhan maupun pengasuh panti asuhan. Karena pelatihan yang kita lakukan dapat membekali santri sebagai bekal wirausaha mandiri setelah keluar dari panti dan dapat dikembangkan menjadi home industi di daerah asal santri.

Pembuatan bedcover kaca (kain perca) tidaklah sulit dan tidak membutuhkan banyak biaya, justru hasil bedcover kaca dapat bernilai jual tinggi. Cara pembuatan bedcover antara lain:

1) Siapkan alat dan bahan Benang, jarum jahit, kain perca batik, kain perca biasa (non batik), gunting, penggaris, dakron, pola;

2) Gambarlah pola dengan menggunakan pensil yang telah di sediakan, kemudian potong sesuai dengan pola;

3) Gunting pola sebanyak mungkin agar mudah mandapatkan pola;

4) Susun kain batik sehingga mendapatkan pola yang bagus;

5) Satukan satu demi satu kain sesuai pola;

6) Jahit kain batik yang sudah di satukan dengan dakron serta kain;

7) Plipit pinggiran agar terlihat rapi.

Dalam pelatihan ini kami membagi anak menjadi 2 kelompok besar dari 30 santri yang kita latih. Mereka sangatlah antusias sngatlah antusias dan tanggap dengan intruksi yang kita berikan. Masalah yang dihadapi pada saat pelatihan santri panti asuhan kurang mampu pada saat menggunakan mesin jahit, karena yang terbiasa menggunakan hanya beberapa anak saja. 


\section{SIMPULAN}

Wirausaha mengajarkan aspek penting kreativitas dan keberanian dengan adanya hal tersebut, kami mengadakan pelatihan bagi santri Panti Asuhan Bina Insani yang kurang mampu sebagai bentuk kontribusi nyata dalam usaha memandirikan dan memberdayakan mereka. Jadi kegiatan pembuatan bedcover kaca sangat perlu dikembangkan karena dapat menjadi bekal keterampilan santri yang dapat bernilai jual tinggi dan menjadikan inovasi baru dalam pembuatan bedcover.

\section{REFERENSI}

Bank Indonesia. (2006). Melangkah bersama membangun UMKM. Jakarta: BI.

Boediono. (2001). Ekonomi makro. Edisi-4. Yogyakarta: BPFE.

Giovany, M. N. (2010). Profil wirausaha muda terdidik pada bisnis butik online studi tentang motivasi berwirausaha, jiwa kewirausahaan dan aspek-aspek manajemen saat memulai usaha dan memasuki pasar ekspor. [Online]. Tersedia: http://www.omahsprei.com/news/46/BedCover-Menghangatkan-Tempat-Tidur-dengan-Keindahan. (12 Maret 2017).

\section{Ucapan Terimakasih}

Tim pelaksana PKM-M mengucapkan terimkasih kepada belmawa DIKTI yang telah mendanai Program Kreatifitas Mahasiswa pelatihan pembutan bedcover kaca (kain perca) di Yayasan Panti Asuhan Bina Insani Ngawi. Terimakasih juga yang kepada yayasan panti asuhan bina insani yang telah memberikan waktunyanya sehingga terselenggaranya pelatihan pembuatan bedcover kaca, tak lupa kepada dosen pembimbing dan pembina yang selalu memberikan arahan kepada tim kami, sehingga kegiatan pelatihan berjalan dengan lancar. 